\title{
The impact of adding community-based distribution of oral contraceptives and condoms to a cluster randomized primary health care intervention in rural Tanzania
}

\author{
Mallory C. Sheff ${ }^{1} \mathbb{D}$, Elizabeth F. Jackson ${ }^{1}$, Almamy M. Kantée 2,3 , Asinath Rusibamayila ${ }^{1}$ and James F. Phillips ${ }^{1 *}$
}

\begin{abstract}
Background: Efforts to expand access to family planning in rural Africa often focus on the deployment of community health agents (CHAs).

Methods: This paper reports on results of the impact of a randomized cluster trial of CHA deployment on contraceptive uptake among 3078 baseline and 2551 endline women of reproductive age residing in 50 intervention and 51 comparison villages in Tanzania. Qualitative data were collected to broaden understanding of method preference, reasons for choice, and factors that explain non-use.

Results: Regression difference-in-differences results show that doorstep provision of oral contraceptive pills and condoms was associated with a null effect on modern contraceptive uptake $[p=0.822 ; \mathrm{Cl} 0.857 ; 1.229]$. Discussions suggest that expanding geographic access without efforts to improve spousal and social support, respect preference for injectable contraceptives, and address perceived risk of side-effects offset the benefits of adopting contraceptives provided by community-based services.

Conclusions: The results of this study demonstrate that increasing access to services does not necessarily catalyze contraceptive use as method choice and spousal dynamics are key components of demand for contraception. Findings attest to the importance of strategies that respond to the climate of demand.
\end{abstract}

Trial registration: Controlled-Trial.com ISRCTN96819844. Retrospectively registered on 29.03.2012.

Keywords: Community health worker, Family planning, Community-based distribution, Tanzania, Primary health care, Reproductive health

\section{Plain English summary}

This paper shares results of a project looking at the contribution of Community Health Agents (CHA) on increasing access to and use of contraceptives in rural Tanzania. Quantitative data for this study included interviewing a total of 3078 baseline and 2551 endline women between the ages of 15 and 49; the qualitative data provided context on women's preferred family planning method, reasons for this choice, and factors that

\footnotetext{
*Correspondence: james.phillips@coumbia.edu

${ }^{1}$ Heilbrunn Department of Population and Family Health, Mailman School of Public Health, Columbia University, 60 Haven Avenue, B2-216, New York, NY 10032, USA

Full list of author information is available at the end of the article
}

explain non-use. Results of the analysis demonstrated that the CHA had no impact on increasing women's use of contraceptives in the study areas. The qualitative data further provided information suggesting that expanding geographic access without improving socio-cultural barriers such as spousal and social support, respecting women's right to choose her preferred method of contraception, and addressing women's perceived risk of side-effects counterweigh the positive effect of providing contraceptives directly in the community. Overall, this study demonstrates that increasing community access of some contraceptive methods by CHAs does not necessarily help improve contraceptive use, and that

(c) The Author(s). 2019 Open Access This article is distributed under the terms of the Creative Commons Attribution 4.0 International License (http://creativecommons.org/licenses/by/4.0/), which permits unrestricted use, distribution, and reproduction in any medium, provided you give appropriate credit to the original author(s) and the source, provide a link to the Creative Commons license, and indicate if changes were made. The Creative Commons Public Domain Dedication waiver (http://creativecommons.org/publicdomain/zero/1.0/) applies to the data made available in this article, unless otherwise stated. 
addressing socio-cultural barriers is just as important to instigate change.

\section{Background}

Despite several decades of policy commitment and investment in programs, the widespread need to improve family planning (FP) services persists in much of rural Africa (1-3). Throughout the region, unaddressed demand for contraception contributes to unintended pregnancy (4), sustained high fertility (5) and stalled transitions $(6,7)$. For four decades, most sub-Saharan countries have pursued policies that attempt to solve this problem with strategies that deploy community workers to distribute care at the community level $(8-10)$. In recent years, this policy has involved shifting a range of public health services to community health workers, including the provision of reproductive health services, thus expanding the pool of trained health workers who are extending the reach of primary health care and family planning to areas where coverage is otherwise sparse (11). Task shifting to improve community-based family planning can also address social constraints to service delivery that are associated with restricting services to clinical environments.

Tanzania is a setting where family planning service reform is urgently needed. Unmet need has remained between 22 and $24 \%$ since 1999 despite ubiquitous clinical service points where care is available at no cost, and only half of demand for family planning (53\%) is satisfied (12). The widespread persistence of non-use is the consequence of a series of interconnected factors that include fears of method side effects (13), shortages of commodities at facilities (14), lack of provider support (15), and social restrictions on the reproductive autonomy of women (16). Misconceptions and fears around contraceptive use are further exacerbated by gender dynamics, which can introduce suspicion and spousal discord (17). Women who are interviewed about non-use also underscore ways in which the social barriers to using family planning services are compounded by the economic costs of taking time to travel to the facility (16).

In response to these challenges, the Tanzanian Ministry of Health Community Development Gender Elderly and Children (MoHCDGEC) launched a health care program in 2007 that sought to improve access to primary health care, including family planning. Known as the Primary Health Care Services Development Program (Mpango wa Maendeleo wa Afya ya Msingi, MMAM), the program called for a single, officially compensated national cadre of community health agents (CHAs) to promote the social and economic well-being of Tanzanians through the provision of quality primary health care services at the community level (18). In order to operationalize the CHA component of the MMAM policy, the Ifakara Health
Institute (IHI), with technical support from Columbia University's Mailman School of Public Health (MSPH) and in collaboration with the Tanzanian Ministry of Health Community Development Gender Elderly and Children (MoHCDGEC), launched a cluster randomized trial in 2010 known as the Connect Project with the goal of testing the demographic impact of deploying paid, professionalized CHAs in three rural Tanzanian districts (19). The current study is an appraisal of this task shifting component on family planning service delivery.

\section{Project setting}

The Connect Project was implemented in Kilombero, Rufiji, and Ulanga, where the IHI Health and Demographic Surveillance System (HDSS) has monitored population dynamics since 1996 in Kilombero and 1998 in Ulanga and Rufiji (Fig. 1) (20). Kilombero and Ulanga are rural, impoverished districts in the Morogoro Region of Tanzania; Rufiji, also rural, is located in the country's Pwani Region. At baseline, the population under observation in the project districts was 360,161, 183,367 of which were in the intervention villages. At endline, the population was $379,264,191,425$ of which were in intervention villages. Despite near universal knowledge of one or more contraceptive method, only $34 \%$ were using a modern method at the time the Connect Project was launched (21).

\section{Study design}

The Connect Project trial used stratified randomization techniques to allocate 50 villages to the intervention group (villages that received CHAs) and 51 villages to the comparison, with a public drawing to assign villages to each group. The village was chosen as the unit of randomization to align the design of the Connect Project with potential national scale-up of the program as implemented by the Ministry of Health (22). Stratification was segmented into four categories based on village population. Villages in the study area differed substantially by distance to nearest health facility and health facility staffing. Intervention villages received between 1 and 4 CHAs based on population size estimated from the 2009 Demographic Surveillance Survey (23). Overall, 80,300 women were exposed to the Connect Project intervention.

A total of 142 CHAs were trained for 9 months, remunerated, and provided with a comprehensive package of primary health care capabilities, including general health promotion, education and referral for facility care, family planning counseling, distribution of oral contraceptive pills and condoms, safe motherhood promotion, essential newborn care, and essential elements of the WHO Integrated Management of Childhood Illness (IMCI) regimen (24). Council Health Management Teams (CHMT) -- including a Connect Project field coordinator, village 


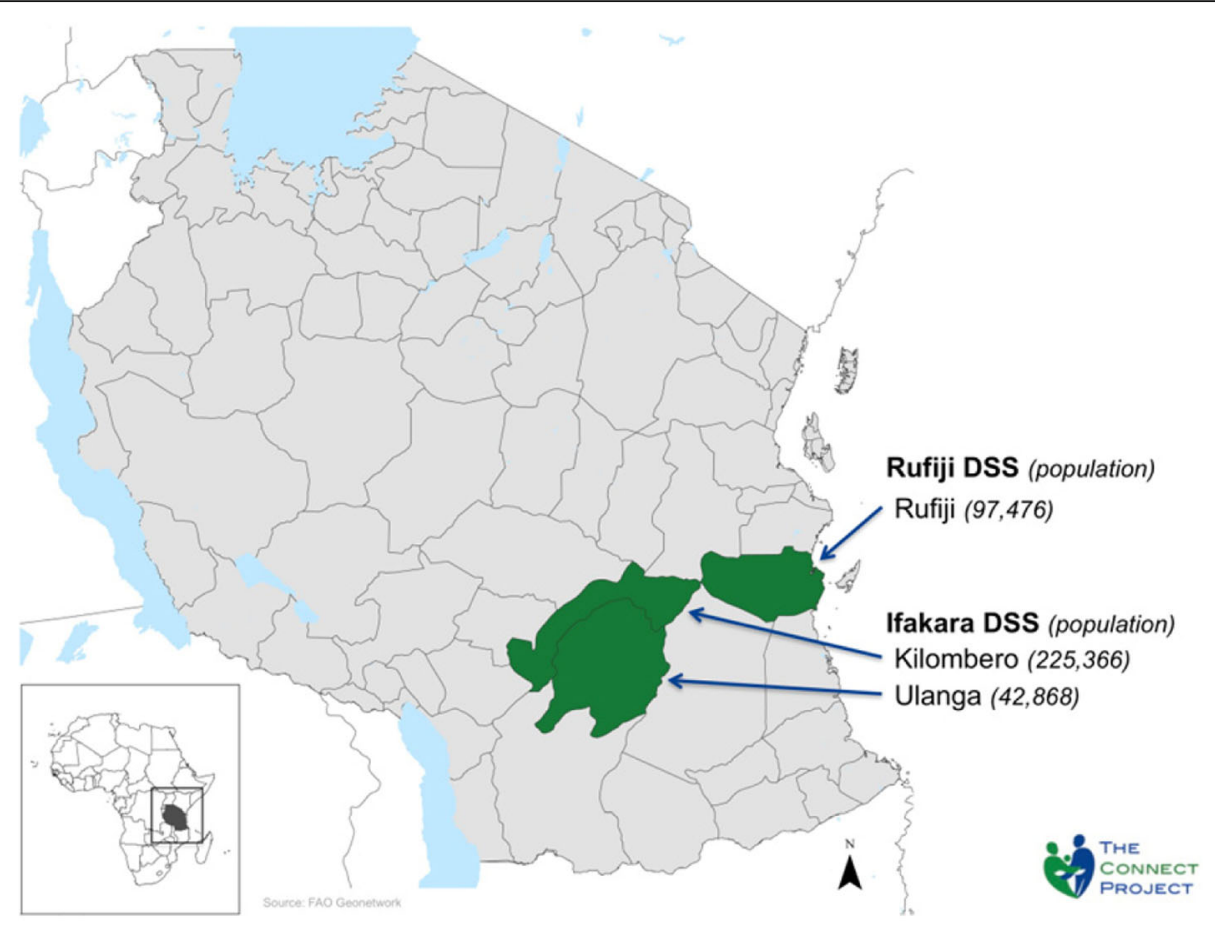

Fig. 1 Map of Connect Study area, Rufiji, Kilombero, and Ulanga districts

authorities, and facility-based health workers-- supervised CHA for their community. Upon deployment, CHA were embedded in local health system structures and became local government employees. They received monthly supportive supervision for their first quarter, and quarterly supervisions afterwards. However, family planning was seen as a component of an integrated $\mathrm{MCH}$ service delivery package and was not exclusively monitored.

\section{Study implementation}

CHA postings in the three study districts ran from $\mathrm{Au}$ gust 2011 through June 2015. CHA services included household visits and the mobilization of men and women groups for topic-specific interventions, including FP. CHA provided FP counseling to dispel method misconceptions, and distributed condoms and oral contraceptive pills for recurring users at the household level in a manner that would respect the need for privacy and address concerns about access. Workers were instructed to refer first time users and clients who sought other methods to the nearest health center or community dispensary, where depot- medroxyprogesterone acetate (DMPA), intra-uterine devices (IUDs), and implants were available (19). The focus on referral for injectable and long acting methods was mandated by policy; as such, the Connect Project CHA were not trained to provide such services.

This paper examines the impact of shifting tasks of CHA to include family planning in their regimen of care.
Given the availability of comprehensive family planning at fixed facilities in Tanzania where their geographic density is intense (25), this study assesses whether there is an incremental effect of doorstep services over and above what is offered at the facility. While dispensary services include the provision of injectables, IUDs, condoms, and oral contraceptive pills, our study examines whether increased community access to contraceptive information and limited methods (pills and condoms) increases use. Using the Connect Project randomized trial as a basis of inference, women in communities randomized to the intervention are hypothesized to have a greater increase of modern contraceptive use over time than women residing in comparison villages.

\section{Methods}

The Connect Project employed a mixed method paradigm involving the conduct of survey research on a random sample of women of reproductive age and a qualitative appraisal of stakeholder reactions to $\mathrm{CHA}$ services.

\section{Quantitative data}

were compiled by two household surveys conducted in Swahili in June 2011, to coincide with the onset of community-based care, and July 2015, at the end of the intervention. The same demographic surveillance system clusters were sampled for baseline and endline survey rounds, but household sampling was independent within 
geographical areas. While individual women of reproductive age (15-49) were interviewed about their demographic, socio-economic, and reproductive health characteristics, including contraceptive use and behavior and pregnancy history, households were the primary sampling unit. A total of 3078 and 2551 women were interviewed on their reproductive health at baseline and endline, respectively.

Independent variables used in the analysis include age, educational attainment, religion, marital status, parity, socio-economic status, and presence or not of a community health agent (CHA). Socioeconomic status was developed using principle component analysis from a series of questions relating to household characteristics such as dwelling unit type, sources of drinking water and type of toilet facility. The outcome variable for the analysis was modern contraceptive use based on the World Health Organization's list of modern contraceptive methods.

Frequency distributions were compiled with differencein-differences (DiD) estimators to estimate the effect of CHA on modern contraceptive use in the period between baseline and endline surveys (27). An extended difference in differences procedure applied to the merged baseline and endline data was estimated to refine statistical adjustment for the possible confounding effect of observed covariates while minimizing the confounding effect of unobserved variables that remain constant over time and that are correlated with CHA presence (28). The estimation procedure assumes that exogenous determinants of contraceptive use that could change over the course of the program affect participants in the treatment and control groups equivalently for merged baseline and endline data as given by the linear model:

$$
\begin{aligned}
{\operatorname{logit~} y_{i j}=} & \beta_{0}+\beta_{1} \text { time }_{i}+\beta_{2} \text { CHA } A_{i}+\beta_{3}\left(\text { time }_{i} *\right. \text { CHA } \\
& +\sum_{j=1}^{J} \gamma_{j} X_{i j}+\varepsilon
\end{aligned}
$$

where $y$ is the log of the odds that individual i with characteristic $j$, will be a current user of any modern contraceptive method and.

time is an indicator of data source for observation i, whereby time $=0$ for observations compiled at the baseline and time $=1$ for cases observed in the endline survey.

CHA is the treatment group dummy for individual $\mathrm{i}$, where $\mathrm{CHA}=1$ if the household is located in a treatment community and $\mathrm{CHA}=0$ otherwise.

$(\mathrm{CHA} *$ time $)$ is the $\mathrm{DiD}$ indicator of the time by treatment interaction.

$\beta_{3}$ is the difference in differences estimator.

$X_{i j}$ is the $\mathrm{j}^{\text {th }}$ control variable for observation $\mathrm{i}$ among a vector of $J$ control variables and $\gamma_{j}$ is the $j^{\text {th }}$ parameter of the J control variables.

All statistical analyses were conducted with STATA 12.1.
Qualitative data were gathered in the Kilombero district in 2013 in response to evidence from Connect Project midline survey research showing that $\mathrm{CHA}$ deployment was not associated with increased contraceptive use, despite community deployment for two years. Interviews from 48 women from 4 focus group discussions (FGDs) and 8 influential community members from in-depth interviews (IDIs) were analyzed. FGDs had an average of 12 individuals, and were interviewed by age group- young women aged 15 to 29 were separated from those aged 30 to 49; 4 men and 4 women were included in the IDIs. Interviewees were recruited by asking village leaders to appoint local focal individuals to help identify individuals for participation.

Qualitative data collection instruments were openended discussion guides that focused on determinants and barriers to primary health care service utilization, knowledge of family planning, perceptions of family planning services, contraceptive utilisation, and other contextual factors contributing to these themes. FGD facilitators were research assistants from Tanzania, fluent in Swahili and local dialects. Interviews were conducted in Swahili, recorded, and transcribed the day of the interviews. The data were then translated into English by bilingual translators and transcribed for analysis. Transcripts were analyzed using a thematic analysis approach in which qualitative analysis is completed in six phases, including: 1) familiarization with and organization of the data, 2) generating initial codes, 3) searching for themes, 4) theme review, 5) defining and naming the themes, and 6) producing a report (29).

\section{Limitations}

Multi-level analyses of the interaction of the health system with the social system would clarify social system determinants of family planning behavior. For example, the needs and perspectives of men, and the impact of male preferences on women's contraceptive behavior, would merit systematic research and appraisal (30-32). Other social determinants of choice and behavior such as socio-cultural norms and societal expectations of behavior would have also warranted further study. The validity of the qualitative research component of this manuscript would have been further strengthened by engaging in group-based coding. One researcher conducted the coding process alone. As a result, inter-rater reliability was not calculable.

\section{Results}

\section{Population characteristics}

Table 1 reports marginal frequency distributions for the descriptive characteristics of women interviewed at baseline and endline by treatment and comparisons villages. Results show that at baseline, the study is generally balanced with 
Table 1 Descriptive characteristics of women at baseline and endline in treatment and comparison areas

\begin{tabular}{|c|c|c|c|c|c|c|c|}
\hline \multirow[t]{2}{*}{ Variable } & & \multicolumn{3}{|l|}{$\begin{array}{l}\text { Baseline } \\
(2011)\end{array}$} & \multicolumn{3}{|l|}{$\begin{array}{l}\text { Endline } \\
(2015)\end{array}$} \\
\hline & & Treatment $=0$ & Treatment = 1 & $p$-value & Treatment $=0$ & Treatment = 1 & $p$-value \\
\hline \multirow[t]{5}{*}{ Age } & $15-24$ & $592(38.6 \%)$ & $595(38.6 \%)$ & 0.11 & $471(37.1 \%)$ & $467(37.3 \%)$ & 0.82 \\
\hline & $25-29$ & $231(15.0 \%)$ & $208(13.5 \%)$ & & $161(12.7 \%)$ & $141(11.3 \%)$ & \\
\hline & $30-34$ & $215(14.0 \%)$ & $243(15.8 \%)$ & & $166(13.1 \%)$ & $173(13.8 \%)$ & \\
\hline & $35-39$ & $242(15.8 \%)$ & $207(13.4 \%)$ & & $173(13.6 \%)$ & 179 (14.3\%) & \\
\hline & $40-49$ & $255(16.6 \%)$ & $287(18.6 \%)$ & & $298(23.5 \%)$ & $292(23.3 \%)$ & \\
\hline \multirow[t]{3}{*}{ Education } & No education & $278(18.1 \%)$ & $281(18.2 \%)$ & 0.86 & $237(18.7 \%)$ & $211(16.9 \%)$ & 0.42 \\
\hline & Less than secondary & 1031 (67.2\%) & $1043(67.7 \%)$ & & $828(65.2 \%)$ & $845(67.5 \%)$ & \\
\hline & Secondary or more & $226(14.7 \%)$ & $216(14.0 \%)$ & & $204(16.1 \%)$ & $196(15.7 \%)$ & \\
\hline \multirow[t]{6}{*}{ Wealth index/ SES Status } & Poorest & 345 (22.5\%) & $424(27.5 \%)$ & $0.003^{* *}$ & $229(18.0 \%)$ & $234(18.7 \%)$ & $0.003^{* *}$ \\
\hline & Poor & $313(20.4 \%)$ & $279(18.1 \%)$ & & $174(13.7 \%)$ & $232(18.5 \%)$ & \\
\hline & Better & $268(17.5 \%)$ & $289(18.8 \%)$ & & $282(22.2 \%)$ & $224(17.9 \%)$ & \\
\hline & Less poor & $343(22.3 \%)$ & $287(18.6 \%)$ & & $228(18.0 \%)$ & $240(19.2 \%)$ & \\
\hline & Least poor & $266(17.3 \%)$ & $261(16.9 \%)$ & & $295(23.2 \%)$ & $276(22.0 \%)$ & \\
\hline & Missing data & - & - & & $61(4.8 \%)$ & $46(3.7 \%)$ & \\
\hline \multirow[t]{4}{*}{ Religion } & Christian & $703(45.9 \%)$ & $740(48.1 \%)$ & 0.053 & $559(44.1 \%)$ & $593(47.4 \%)$ & $0.009^{* *}$ \\
\hline & Muslim & $774(50.5 \%)$ & 765 (49.7\%) & & $634(50.0 \%)$ & $618(49.4 \%)$ & \\
\hline & Traditional/ Other & $53(3.5 \%)$ & $35(2.3 \%)$ & & $73(5.8 \%)$ & 39 (3.1\%) & \\
\hline & No response/ missing & & & & $3(0.2 \%)$ & $2(0.2 \%)$ & \\
\hline \multirow[t]{4}{*}{ Parity } & 0 & 344 (22.4\%) & $325(21.1 \%)$ & 0.20 & 349 (27.5\%) & 346 (27.6\%) & 0.59 \\
\hline & $1-2$ & 419 (27.3\%) & $439(28.5 \%)$ & & 345 (27.2\%) & $312(24.9 \%)$ & \\
\hline & $3-4$ & 394 (25.7\%) & $358(23.3 \%)$ & & $282(22.2 \%)$ & $288(23.0 \%)$ & \\
\hline & $5+$ & $378(24.6 \%)$ & $417(27.1 \%)$ & & $293(23.1 \%)$ & 306 (24.4\%) & \\
\hline \multirow[t]{6}{*}{ Marital status } & Married & $820(53.4 \%)$ & $856(55.6 \%)$ & 0.84 & $597(47.0 \%)$ & $620(49.5 \%)$ & 0.23 \\
\hline & Living with partner & $172(11.2 \%)$ & $162(10.5 \%)$ & & $165(13.0 \%)$ & $156(12.5 \%)$ & \\
\hline & Divorced & 87 (5.7\%) & 87 (5.6\%) & & $77(6.1 \%)$ & $94(7.5 \%)$ & \\
\hline & Widowed & $33(2.1 \%)$ & $28(1.8 \%)$ & & $28(2.2 \%)$ & $31(2.5 \%)$ & \\
\hline & Single & $421(27.4 \%)$ & 406 (26.4\%) & & $400(31.5 \%)$ & 347 (27.7\%) & \\
\hline & No response/ Missing & $2(0.1 \%)$ & $1(0.1 \%)$ & & $2(0.2 \%)$ & $4(0.3 \%)$ & \\
\hline \multicolumn{2}{|l|}{ Modern use of FP } & 496 (32.3\%) & $508(33.0 \%)$ & 0.69 & $388(30.6 \%)$ & $393(31.4 \%)$ & 0.66 \\
\hline \multicolumn{2}{|l|}{ Number of respondents } & 1535 & 1540 & & 1269 & 1252 & \\
\hline
\end{tabular}

${ }^{* *} p<0.01$

the exception of a statistically significant difference in wealth index $(p<0.003)$ and slight difference in religion $(p<0.053)$. As per Table 1, while significant, the effect size difference for the latter is quite small. Overall, the majority of women at baseline are under the age of 30 (53.6 and $52.1 \%$ in control and treatment areas, respectively), have completed less than secondary education, and are married. Women living in the poorest households (1st wealth quintile) comprised 22.5 and $27.5 \%$ of the respondents in comparison and treatment villages, respectively.

At endline, differences between treatment and control areas are statistically significant with respect to socioeconomic status $(p=0.003)$ and religion $(p=0.009)$. Almost half of women interviewed were under 30 (49.8\% in comparison villages and $48.6 \%$ in treatment villages) and married (47\% in comparison villages and $49.5 \%$ in treatment villages).

\section{Modern contraceptive use}

Results in Table 2 present modern contraceptive use by covariate at baseline and endline. Women aged 15-24 have a higher prevalence of modern contraceptive relative to older women with $32 \%$ using a modern method at baseline, and $23 \%$ at endline. Likewise, women with 
Table 2 Modern contraceptive prevalence by covariate at baseline and endline

\begin{tabular}{|c|c|c|c|c|c|c|c|}
\hline \multirow[t]{2}{*}{ 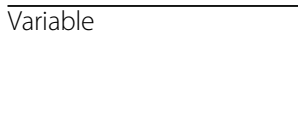 } & & \multicolumn{3}{|l|}{$\begin{array}{l}\text { Baseline } \\
(2011)\end{array}$} & \multicolumn{3}{|l|}{$\begin{array}{l}\text { Endline } \\
2015\end{array}$} \\
\hline & & $\overline{M o d} F P=0$ & Mod FP $=1$ & $p$-value & $\overline{M o d} F P=0$ & Mod FP $=1$ & $p$-value \\
\hline \multirow[t]{5}{*}{$\overline{\text { Age }}$} & $15-24$ & $869(42.0 \%)$ & $318(31.7 \%)$ & $<0.001^{*}$ & $770(43.8 \%)$ & $181(22.8 \%)$ & $<0.001^{* *}$ \\
\hline & $25-29$ & 257 (12.4\%) & $182(18.1 \%)$ & & 175 (10.0\%) & 129 (16.3\%) & \\
\hline & $30-34$ & $258(12.5 \%)$ & 200 (19.9\%) & & $191(10.9 \%)$ & $152(19.2 \%)$ & \\
\hline & $35-39$ & $278(13.4 \%)$ & $171(17.0 \%)$ & & $196(11.1 \%)$ & $160(20.2 \%)$ & \\
\hline & $40-49$ & 409 (19.7\%) & $133(13.2 \%)$ & & $426(24.2 \%)$ & $171(21.6 \%)$ & \\
\hline \multirow[t]{3}{*}{ Education } & No education & $418(20.2 \%)$ & $141(14.0 \%)$ & $<0.001^{* *}$ & $321(18.3 \%)$ & $134(16.9 \%)$ & $<0.001^{* *}$ \\
\hline & Less than secondary & $1341(64.7 \%)$ & $733(73.0 \%)$ & & $1112(63.3 \%)$ & 579 (73.0\%) & \\
\hline & Secondary or more & $315(15.2 \%)$ & $130(12.9 \%)$ & & $325(18.5 \%)$ & $80(10.1 \%)$ & \\
\hline \multirow[t]{6}{*}{ Wealth index/ SES Status } & Poorest & $543(26.2 \%)$ & $226(22.5 \%)$ & $<0.032^{*}$ & $312(17.7 \%)$ & $153(19.3 \%)$ & $<0.001^{* *}$ \\
\hline & Poor & $395(19.0 \%)$ & $197(19.6 \%)$ & & $288(16.4 \%)$ & $127(16.0 \%)$ & \\
\hline & Better & $352(17.0 \%)$ & $205(20.4 \%)$ & & $320(18.2 \%)$ & $195(24.6 \%)$ & \\
\hline & Less poor & $438(21.1 \%)$ & $192(19.1 \%)$ & & $356(20.3 \%)$ & $121(15.3 \%)$ & \\
\hline & Least poor & $343(16.5 \%)$ & $184(18.3 \%)$ & & $396(22.5 \%)$ & $176(22.2 \%)$ & \\
\hline & Missing data & $3(0.1 \%)$ & $0(0.0 \%)$ & & $86(4.9 \%)$ & $21(2.6 \%)$ & \\
\hline \multirow[t]{4}{*}{ Religion } & Christian & $955(46.2 \%)$ & $488(48.6 \%)$ & $<0.001^{* *}$ & $783(44.5 \%)$ & $380(47.9 \%)$ & $<0.001^{* *}$ \\
\hline & Muslim & 1025 (49.5\%) & $514(51.2 \%)$ & & $863(49.1 \%)$ & 407 (51.3\%) & \\
\hline & Traditional/ Other & $86(4.2 \%)$ & $2(0.2 \%)$ & & $106(6.0 \%)$ & $6(0.8 \%)$ & \\
\hline & No response/ Missing & $3(0.1 \%)$ & $0(0.0 \%)$ & & $6(0.3 \%)$ & $0(0.0 \%)$ & \\
\hline \multirow[t]{4}{*}{ Parity } & 0 & $565(27.3 \%)$ & 107 (10.7\%) & $<0.001^{* *}$ & $561(31.9 \%)$ & $143(18.0 \%)$ & $<0.001^{* *}$ \\
\hline & $1-2$ & $545(26.3 \%)$ & $313(31.2 \%)$ & & 449 (25.5\%) & $218(27.5 \%)$ & \\
\hline & $3-4$ & $454(21.9 \%)$ & $298(29.7 \%)$ & & $351(20.0 \%)$ & $221(27.9 \%)$ & \\
\hline & $5+$ & $509(24.6 \%)$ & $286(28.5 \%)$ & & 397 (22.6\%) & $211(26.6 \%)$ & \\
\hline \multirow[t]{6}{*}{ Marital status } & Married & 1066 (51.5\%) & $610(60.8 \%)$ & $<0.001^{* *}$ & 805 (45.8\%) & $426(53.7 \%)$ & $<0.001^{* *}$ \\
\hline & Living with partner & 206 (9.9\%) & $128(12.7 \%)$ & & $193(11.0 \%)$ & $132(16.6 \%)$ & \\
\hline & Divorced & $126(6.1 \%)$ & $48(4.8 \%)$ & & $115(6.5 \%)$ & $60(7.6 \%)$ & \\
\hline & Widowed & $46(2.2 \%)$ & $15(1.5 \%)$ & & $49(2.8 \%)$ & $10(1.3 \%)$ & \\
\hline & Single & $625(30.2 \%)$ & $202(20.1 \%)$ & & $590(33.6 \%)$ & 165 (20.8\%) & \\
\hline & No response/ Missing & $2(0.1 \%)$ & $1(0.1 \%)$ & & $6(0.3 \%)$ & $0(0.0 \%)$ & \\
\hline In Treatment areas & & $1032(49.8 \%)$ & $508(50.6 \%)$ & 0.69 & 859 (49.4\%) & 393 (50.3\%) & 0.66 \\
\hline Number of Respondents & & 2074 & 1004 & & 1758 & 793 & \\
\hline
\end{tabular}

${ }^{* *} p<0.01$

some education were more frequent users of contraception than women with no education, with $73 \%$ of users at baseline and endline; contraceptive use prevalence was comparable by religion.. Married women were more prevalent users of modern methods than unmarried women living with a partner or divorced, widowed, or single women.

Table 3 further details contraceptive use by method type at baseline and endline by treatment and comparison village. The decrease in use of oral contraceptive pills at endline in both the treatment and comparison villages is notable, despite distribution of this method by
CHA at the doorstep level. The increased use of implants is furthermore notable with a nearly twofold increase between baseline and endline; there is, however, no significant difference between treatment and control villages. In general, oral contraceptive pills, injectables, and implants are the most used modern contraceptive methods for women in our project area, with injectables the clear contraceptive method of choice.

\section{Difference in differences estimation}

Table 4 presents the DiD model showing baselineendline differences with period effects capturing 
Table 3 Modern contraceptive use at baseline and endline by treatment and control areas

\begin{tabular}{|c|c|c|c|c|}
\hline \multirow[t]{2}{*}{ Variable } & \multicolumn{2}{|l|}{$\begin{array}{l}\text { Baseline } \\
\text { (2011) }\end{array}$} & \multicolumn{2}{|l|}{$\begin{array}{l}\text { Endline } \\
\text { (2015) }\end{array}$} \\
\hline & Treatment $=0$ & Treatment $=1$ & Treatment $=0$ & Treatment $=1$ \\
\hline emale Sterilization & $22(1.42 \%)$ & $24(1.68 \%)$ & $25(1.97 \%)$ & $28(2.24 \%)$ \\
\hline Male Sterilization & $1(0.06 \%)$ & $4(0.28 \%)$ & - & - \\
\hline Pill & $124(8.02 \%)$ & $126(8.81 \%)$ & 77 (6.07\%) & $67(5.35 \%)$ \\
\hline IUD & $16(1.03 \%)$ & $17(1.19 \%)$ & $18(1.42 \%)$ & $17(1.36 \%)$ \\
\hline Injectables & $216(13.97 \%)$ & $197(13.78 \%)$ & $148(11.66 \%)$ & $178(14.22 \%)$ \\
\hline Implants & $38(2.46 \%)$ & $28(1.96 \%)$ & $58(4.57 \%)$ & $46(3.67 \%)$ \\
\hline Male Condom & $63(4.08 \%)$ & $63(4.41 \%)$ & $51(4.02 \%)$ & $46(3.67 \%)$ \\
\hline Female Condom & $5(0.32 \%)$ & $5(0.35 \%)$ & $1(0.08 \%)$ & $1(0.08 \%)$ \\
\hline Emergency Contraception & $1(0.06 \%)$ & 0 & $2(0.16 \%)$ & $2(0.16 \%)$ \\
\hline Lactation Amenorrhea Method & 0 & $1(0.07 \%)$ & $4(0.32 \%)$ & $2(0.16 \%)$ \\
\hline Other Modern Method & $7(0.45 \%)$ & $11(0.77 \%)$ & $4(0.32 \%)$ & $6(0.48 \%)$ \\
\hline Total & 1546 & 1430 & 1269 & 1252 \\
\hline
\end{tabular}

temporal change, and the treatment-period interaction representing the $\mathrm{DiD}$. Other rows of Table 4 present nuisance parameters that adjust for age, educational attainment, religion, marital status, socio-economic status, and parity. Results show that the difference-in-difference estimates no effect of the presence of community health workers on modern contraceptive use $[p=0.822$; CI $0.819 ; 1.286]$.

\section{Qualitative data}

Qualitative data were compiled to provide a deeper understanding of community acceptance of CHA, women's method preference, and reasons for this preference as factors that could explain why CHA did not have an effect on women's modern contraceptive uptake despite community engagement for four years.

\section{CHA acceptance in the community}

CHA acceptance in intervention communities was overwhelmingly positive, with both $\mathrm{CHA}$ and community members reporting good community engagement and exchanges. CHA felt welcomed by community members who did not express fear or discontent with their services.

Facilitator: To what extent does the community accept your services?

Respondent: In fact, the community has received us positively (...) they have seen the advantages [of our services]. For example, environmental cleanliness, family planning, and the treatment of children under the age of 5 years. They [the community] respond positively because they have seen the advantages.

\section{F: How have they received the services?}

$R$ : They have received these services positively to a large extent because they are using them and the education that we have given them is applied.

F: Have you ever received complaints or fear from the community towards your services?

\section{R: In fact, that has never happened.}

As above, women and men reported accepting $\mathrm{CHA}$ into their communities. Many were grateful for the health and educational services provided the CHA.

Respondent: No one fears them [CHAs], everybody is satisfied based on their performance. In fact, these CHAs are trying their level best and they are doing a good job.

Facilitator: there is no one who has a fear or worries?

P6: No one has any fear or anxiety.

In short, we don't have any fear with CHAs, we accept them and we want them to proceed with their job. We like them.

Interaction with $\mathrm{CHA}$ on family planning education and the provision of condoms and pills was also positively received by community members. 
Table 4 Regression difference-in-differences (DiD) estimates of the impact of CHAs on modern contraceptive use adjusting for the effects of socio-demographic covariates

\begin{tabular}{|c|c|c|c|c|}
\hline \multirow{2}{*}{$\begin{array}{l}\text { Covariates } \\
\text { DiD (Ref: Baseline) }\end{array}$} & \multirow[t]{2}{*}{ Odds Ratio } & \multirow[t]{2}{*}{$P>\mathrm{t}$} & \multicolumn{2}{|c|}{ [95\% Conf. Interval] } \\
\hline & & & & \\
\hline Post (Endline) & 1.026 & 0.779 & .857 & 1.229 \\
\hline \multicolumn{5}{|l|}{ Village (Ref: Control Village) } \\
\hline Treatment Village & 1.000 & 0.999 & .839 & 1.191 \\
\hline DiD Interaction (Post*Treatment) & 1.026 & 0.822 & .819 & 1.286 \\
\hline Age & 1.456 & $0.000^{* *}$ & 1.387 & 1.528 \\
\hline Age squared & .994 & $0.000^{* *}$ & .993 & .995 \\
\hline \multicolumn{5}{|l|}{ Education (ref: no education) } \\
\hline Less than secondary education & 1.438 & $0.000^{* *}$ & 1.202 & 1.719 \\
\hline Secondary education or more & 1.480 & $0.002^{* *}$ & 1.154 & 1.898 \\
\hline \multicolumn{5}{|l|}{ Religion (Ref: Christian) } \\
\hline Muslim & 1.000 & 0.992 & .879 & 1.140 \\
\hline Traditional or other & .072 & $0.000^{* *}$ & .035 & .149 \\
\hline \multicolumn{5}{|l|}{ Marital Status (Ref: Married) } \\
\hline Living with partner & 1.154 & 0.159 & .946 & 1.409 \\
\hline Divorced & .739 & $0.015^{*}$ & .580 & .942 \\
\hline Widowed & .567 & $0.003^{* *}$ & .388 & .828 \\
\hline Single & .847 & 0.073 & .707 & 1.016 \\
\hline \multicolumn{5}{|l|}{ Wealth Quintile (Ref: Poorest) } \\
\hline Poor & 1.013 & 0.909 & .806 & 1.274 \\
\hline Better & 1.299 & $0.004^{* *}$ & 1.086 & 1.553 \\
\hline Less Poor & .940 & 0.591 & .751 & 1.177 \\
\hline Least Poor & 1.101 & 0.422 & .871 & 1.392 \\
\hline Parity & 1.075 & $0.000^{* *}$ & 1.035 & 1.118 \\
\hline _cons & .002 & $0.000^{* *}$ & .001 & .003 \\
\hline
\end{tabular}

Summary statistics * $p<0.05 * * p<0.01$

Observations: 5469

Wald chi2 (18) 522.36

Prob > chi2 0.000

Pseudo $\mathrm{R}^{2}: 0.0718$

I interact with CHAs in the issue of family planning, so when I need (something), they come to give me education. They can also provide me with pills or condoms, they can advise me on the methods I want to use, or they can mention all methods and I can choose the preferred one because they help.

\section{Contraceptive method preference}

Despite overwhelming acceptance of $\mathrm{CHA}$ in the community, their limited distribution of condoms and oral contraceptive pills to recurring users did not align with women's method preference. The favored contraceptive methods cited in the interviews were pills and DMPA, with overall preference for injectables. Indeed, while interviewees often cited both contraceptive methods, apprehension about missing a day offset women's desire to use oral contraception:

Others don't prefer using pills because they worry that they will forget to take the pills daily. So they prefer to take injections because these last for three months.

You know, every drug of family planning has it fans, you may find others they tell you 'I like pills more' but there are very few. You may also find someone tell you to swallow pills every day is a problem if you travel. Me, I see injection is best because you get injection which works after three months (... ). Many young girls use injections more. 
In general, women tended to favor family planning methods that could be pursued in secret, away from the husband's knowledge. In the traditional setting of rural Tanzania, as in gender stratified traditional settings elsewhere in rural sub-Saharan Africa, men attempt to control household fertility decisions:

Most of the time, I should be honest, the man is the one who makes the decision, and if is not, then he will think something wrong.

In my opinion, others have a lot of children because they are not allowed to use family planning pills. [(Facilitator: Who restricts them?] Their partners.

Injections were thus preferred because their discreet application permits secrecy from their husbands' knowledge. Unlike pills, which women have to take daily in their homes, injectable contraceptives (DMPA) are done once every three months at the facility:

They [men] want [child] bearing. So they make women use [contraceptives] in secret. A woman may pretend she is sick, she may go to hospital and the nurse gives her an injection. And injections don't show any sign that you have gotten it (... ).

\section{If your husband did not understand [about family planningl you will use injection (... ).}

While women highlighted the importance of surreptitious use of family planning, they also underscored the socio-cultural barriers that foster this concern. Interviewees believed that if family planning promotional and educational activities could focus on couples rather than individual women, such encounters would enhance the social acceptability of family planning use:

Men should also be given education like this, because some men are so against contraceptives. They say family planning is against God, because God gives you the capability to reproduce, and if you force him to use contraceptives, you will be beaten and you should conceive.

We can use CHA at the time when they come. There should be announcements that CHA will be at certain area certain days, so every man and woman should attend. As you know nowadays even men are supposed to attend the clinic so as to be aware what their wives have been told. Other men have a clear

understanding, so when they receive such education

they agree with family planning methods.

\section{Discussion}

The aim of this study was to assess the incremental impact of deploying professionally trained community health workers to dispense oral contraceptive pills and condoms at the household level in three rural districts of Tanzania. The strategic design of the project was compliant with official policies that constrain the range of services that community-based workers are allowed to provide. Oral contraceptive pill users were required to initiate use in clinics and dispensaries; $\mathrm{CHA}$, in turn, were restricted to resupplying existing users and informational exchanges with potential new users. DMPA was available in nearby clinics and dispensaries, but nonclinical household and community-based services delivered by CHA did not provide this or other long-acting methods. The operational model of official policy therefore constrained the range of services CHA could provide.

Results demonstrate that the deployment of paid, professional CHA who provided family planning education, oral contraceptive pills, and barrier methods at the doorstep did not engender increased contraceptive use over and above levels of family planning practice that were observed in comparison communities, despite $61 \%$ of respondents reporting being visited by a $\mathrm{CHA}$ in the last 3 months. Findings bring into question the efficacy of policies that attempt to expand access to family planning without also expanding the range of contraceptive methods. Studies on the provision of injectable family planning services by community workers have been conducted in Ethiopia, Uganda, Kenya, Senegal, Ghana, Malawi, Nigeria and elsewhere (33-35). And, following a technical consultation review, the World Health Organization (WHO), the United States Agency for International Development (USAID), and Family Health International (FHI) concluded that evidence supports the introduction and scale-up of community-based DMPA, with support for its inclusion in policy and operational guidelines in developing countries (36). In countries with rapid contraceptive uptake, this has resulted in a 50 to $75 \%$ utilization of injectables as women's family planning method of choice (37).

Improving method access also involves strategies for improving social access to contraception. In particular, mapping and understanding the social context when designing family planning programs requires strategic planning on how best to involve men in the process of ensuring the social acceptability of contraceptive services and practice $(38,39)$. Our findings on the importance of 
gender inclusion are not new: Three decades ago, Easterlin and colleagues posited a framework that specified the importance of mitigating social and spousal constraints to fertility regulation $(40,41)$. Gender sensitive programming remains important in ensuring a comprehensive approach to social acceptance of family planning utilization (42). Yet, while social access to family planning services is important, social, demographic, and behavioral research in Tanzania and elsewhere has consistently demonstrated the importance of maximizing the range of contraceptive options alongside increased access to care $(43,44)$. Expanding method options contributes to the goal of improving the quality of care (45, 46), reproductive rights, and social acceptability of contraception (47).

With so much evidence to support policies that expand choice and improve social support for family planning, why is more research on this topic needed? The Connect Project results attest to the incongruence of Tanzania's restriction on the range of methods that community workers are allowed to provide with the method preferences of the population that such workers serve. A truly comprehensive program would be an integrated approach to primary health care with community-engagement of social networks that addresses the socio-cultural environment $(48,49)$, including the concerns of men and behavioral expectations, while also providing doorstep access to a range of methods that respects the preferences of women.

\section{Conclusion}

The hypothesis that contraceptive use will increase if access to a limited range of FP services is provided by community-based care is often accepted without consideration of the socio-cultural factors that define the climate of demand. The results of this study demonstrate that increasing access to services does not necessarily catalyze contraceptive use; method choice and spousal dynamics are some of the key components of FP demand. The importance of including gender strategies that respond to the demand for methods that permit covert use is also emphasized. These findings invite review of Tanzania's operational policies that restrict the role of community workers, with a focus on implementation research conducted elsewhere in Africa and three decades ago in Asia (50-53). Social factors that prevent women from using their family planning method of choice invite policies that offset such constraints with convenient access to the full range of methods that community workers can offer. Studies fielded in East and Southern Africa show that expanding the range of methods provided by community-based services beyond one or two can provide additional benefits to women in need of care, even if these methods are readily available in clinics and dispensaries.

\section{Abbreviations}

CHA: Community Health Agent; CHMT: Council Health Management Teams; DMPA: Depot- medroxyprogesterone acetate; FGD: Focus group discussions; FHI: Family Health International; FP: Family Planning; HDSS: Health and Demographic Surveillance System; IDI: In-depth interviews; IHI: Ifakara Health Institute; IMCI: Integrated Management of Childhood IIIness; IUD: Intrauterine device; MoHCDGEC: Tanzanian Ministry of Health Community Development Gender Elderly and Children; MSPH: Mailman School of Public Health; USAID: United States Agency for International Development

\section{Acknowledgements}

The authors gratefully acknowledge the contribution of Ifakara Health Institute Connect team members to the development and execution of the project intervention and research program. The authors also acknowledge scientists who contributed to designing the study: Salim Abdulla, Hassan Mshinda, Godfrey Mbaruku, Fatuma Manzi, Selemani Mbuyita, Honorati Masanja, Senga Pemba, Stephane Helleringer, Kate Ramsey, Lynn Freedman, Don deSavigny and Joanna Schellenberg.

\section{Author's contributions}

The Principal Investigator (JFP), the lead author (MCS), and EFJ had full access to the study data and undertook joint responsibility for the preparation and submission of the paper for publication. MCS, JFP, and EFJ conceived of the design and approach of the paper. AMK and AR managed research operations in Tanzania. MCS and EFK analyzed the data and JFP contributed to the preparation of this manuscript. MCS wrote the first draft of the manuscript. All authors contributed to data interpretation, revisions and approval of the final version.

\section{Funding}

The United States based Doris Duke Charitable Foundation (DDCF) Inc. financed the trial under grant number 2009058. Advisors to the DDCF commented on the study design prior to implementation. During the trial, all data collected, processed, and analyzed by the project staff, were shared with the Population Health Implementation training and Data collaborative located at the John Hopkins University for data quality assurance analyses. Interim analyses were pre-specified and provided in confidence to the data collaborative, which met in July 2013, reviewed the interim analyses, and recommended continued operation of the project.

\section{Availability of data and materials}

Africa Health Initiative coordination mechanisms sponsored by the Doris Duke Charitable Foundation supported a Data Cooperative for organizing international access to Africa Health Initiative project data sets. The project protocol and data used for this analysis and data collection instruments are available upon written request to the Data Cooperative by emailing the lead author of this publication, with a copy to the corresponding author. Data of the Connect Project are described at https://www.jhsph.edu/research/ centers-and-institutes/institute-for-international-programs/_documents/phit_ concept.pdf. Core indicators for this study are displayed at:

https://dataverse.harvard.edu/file.xhtml?persistentld=doi:10.7910/DVN/26539/ PN40RD.

\section{Ethics approval and consent to participate}

The service operational plan, training program and data collection procedure was reviewed and approved by the ethical review committees of the Tanzania MoHCDGEC, the National Medical Research Coordination Committee of the National Institute for Medical Research, and the IHI's Institutional Review Board (NIMR/HQ/R.8a/Nol.IX/1203). Connect Project investigators sought authorization for use of data from the $\mathrm{IHI}$ through the Connect project (Ifakara Health Institute Internal Review Board No.16-2010). Ethical clearance for the analysis was also accorded by the Columbia University Medical Center Institutional Review Board (Protocol-AAAF3452).

\section{Consent for publication}

Not applicable.

\section{Competing interests}

None. 


\section{Author details}

${ }^{1}$ Heilbrunn Department of Population and Family Health, Mailman School of Public Health, Columbia University, 60 Haven Avenue, B2-216, New York, NY 10032, USA. Ifakara Health Institute, Mikocheni, Dar-es-Salaam, Tanzania. ${ }^{3}$ Department of International Health Division of Global Disease Epidemiology and Control, Institute for International Programs Bloomberg School of Public Health, Johns Hopkins University, Baltimore, MD, USA.

Received: 15 July 2019 Accepted: 13 November 2019 Published online: 19 December 2019

\section{References}

1. Casterline JB, Sinding SW. Unmet need for family planning in developing countries and implications for population policy. Popul Dev Rev. 2000;26(4): $691-723$.

2. Cleland JG, Ndugwa RP, Zulu EM. Family planning in sub-Saharan Africa: progress or stagnation? Bull World Health Organ. 2011;89:137-43.

3. Cleland J, Bernstein S, Ezeh A, Faundes A, Glasier A, Innis J. Sexual and reproductive health 3 - family planning: the unfinished agenda. Lancet. 2006;368(9549):1810-27.

4. Hubacher D, Mavranezouli I, McGinna E. Unintended pregnancy in subSaharan Africa: magnitude of the problem and potential role of contraceptive implants to alleviate it. Contraception. 2008;78(1):73-8.

5. Bongaarts J. Africa's Unique Fertility Transition. Popul Dev Rev. 2016; Supplement:1-20.

6. Bongaarts J, Casterline J. Fertility transition: is sub-Saharan Africa different? Popul Dev Rev. 2013;38(SUPPL.1):153-68.

7. Casterline JB, El-Zeini LO. Unmet need and fertility decline: a comparative perspective on prospects in sub-Saharan Africa. Stud Fam Plan. 2014;45(2):227-45.

8. Hoke TH, Wheeler SB, Lynd K, Green MS, Harimalala B, Razafindravony H, et al. Community-based provision of injectable contraceptives in Madagascar: 'task shifting' to expand access to injectable contraceptives. Health Policy Plan. 2012;27(1):52-9.

9. Dawson AJ, Buchan J, Duffield C, Homer CSE, Wijewardena K. Task shifting and sharing in maternal and reproductive health in low-income countries: a narrative synthesis of current evidence. Health Policy Plan. 2013 May;8.

10. Walford V. A review of health sector wide approaches in Africa. Vol. 44 Strategy. 2007.

11. Scott VK, Gottschalk LB, Wright KQ, Twose C, Bohren MA, Schmitt ME, et al. Community health workers' provision of family planning Services in lowand Middle-Income Countries: a systematic review of effectiveness. Stud Fam Plan. 2015;46(3):241-61.

12. Tanzania Demographic and Health Survey and Malaria Indicator Survey (TDHS-MIS) 2015-16. Dar es Salaam, Tanzania, Rockville, Maryl USA [Internet]. 2016;172-3. Available from: https://www.dhsprogram.com/pubs/ pdf/FR321/FR321.pdf

13. Arends-Kuenning M, Kessy FL. The impact of demand factors, quality of care and access to facilities on contraceptive use in Tanzania. J Biosoc Sci. 2007 Jan 1;39(1):1-26.

14. Speizer IS, Hotchkiss DR, Magnani RJ, Hubbard B, Nelson K. Do Service providers in Tanzania unnecessarily restrict clients' access to contraceptive methods? Int Fam Plan Perspect. 2000;26(1):13-20.

15. Eriksen J, Nsimba SED, Minzi OMS, Sanga AJ, Petzold M, Gustafsson LL, et al. Adoption of the new antimalarial drug policy in Tanzania--a cross-sectional study in the community. Tropical Med Int Health. 2005 Oct;10(10):1038-46.

16. Rusibamayila A, Phillips J, Kalollela A, Jackson E, Baynes C. Factors influencing pregnancy intentions and contraceptive use: an exploration of the "unmet need for family planning" in Tanzania. Cult health sex [internet]. 2016;1058(July):1-16. Available from. http://www.ncbi.nlm.nih.gov/ pubmed/27297661.

17. Mosha I, Ruben R, Kakoko D. Family planning decisions, perceptions and gender dynamics among couples in Mwanza. Tanzania: Qual Study BMC Public Health. 2013;13:523.

18. United Republic of Tanzania. The Primary Health Care Improvement Programme (MMAM). Dar-es-Salaam; 2007.

19. Ramsey K, Hingora A, Kante M, Jackson EF, Exavery A, Pemba S, et al. The Tanzania Connect Project: a cluster-randomized trial of the child survival impact of adding paid community health workers to an existing facilityfocused health system. BMC Health Serv Res. 2013;13(Supplement 2):S6. https://doi.org/10.1186/1472-6963-13-S2-S6.
20. Ramsey K, Hingora A, Kante M, Jackson E, Exavery A, Pemba S, et al. The Tanzania Connect Project: a cluster-randomized trial of the child survival impact of adding paid community health workers to an existing facilityfocused health system. BMC Health Serv Res [Internet]. 2013 Jan [cited 2014 Jan 31];13 Suppl 2(SUPPL.2):S6. Available from: http://www.scopus.com/ inward/record.url?eid=2-s2.0-84878577973\&partnerlD=tZOtx3y]

21. Macro NB of S (NBS) [Tanzania] and ICF. Tanzania Demographic and Health Survey 2010. Dar es Salaam, Tanzania: NBS and ICF Macro; 2011.

22. Ramsey K, Hingora M, Kante M, Jackson EF, Exavery A, Pemba S, et al. The Tanzania Connect Project: A cluster-randomized trial of the child survival impact of adding paid community health workers to an existing facilityfocused health system. BioMed Cent Heal Serv Res. 2013;13(Supplement 2):S6.

23. Kanté AM, Exavery A, Jackson EF, Kassimu T, Baynes CD, Hingora A, Phillips JF. The impact of paid community health worker deployment on child survival: the connect randomized cluster trial in rural Tanzania. BMC Health Serv Res. 2019;19(1):492. https://doi.org/10.1186/ s12913-019-4203-1.

24. World Health Organization. Handbook IMCl: Integrated Management of Childhood Illness. World Health Organ. 2005:163.

25. Kadobera D, Sartorius B, Masanja H, Mathew A, Waiswa P. The effect of distance to formal health facility on childhood mortality in rural Tanzania, 2005-2007. Glob Health Action. 2012 Jan;5:1-9.

26. Tanzania Bureau of Statistics and Macro International, (Measure DHS). Tanzania Demographic and Health Survey. National Bureau of Statistics Dar es Salaam, Tanzania ICF Macro Calverton, Maryland, USA. 2010.

27. Heckman J. Effects of child-care programs on women's work effort. J Polit Econ. 1974;82:136-63.

28. Buckley J, Shang Y. Estimating policy and program effects with observational data: the "differences-in-differences" estimator. Pract Assessment, Res Eval. 2003:8(24):1-8.

29. Braun V, Clarke V. Using thematic analysis in psychology. Qual Res Psychol. 2006:3(2):77-101.

30. Bawah AA, Akweongo P, Simmons R, Phillips JF. Women's fears and men's anxieties: the impact of family planning on gender relations in northern Ghana. Stud Fam Plann. 1999/04/27. 1999;30(1):54-66.

31. Bawah A. Spousal communication and family planning behavior in Navrongo: a longitudinal assessment. Stud Fam Plan. 2002;33(2):185-94.

32. Hossain MB, Phillips JF, Mozumder ABMKA. The effect of husbands' fertility preferences on couples' reproductive behaviour in rural Bangladesh. J Biosoc Sci. 2007;25:455-64.

33. Weidert K, Gessessew A, Bell S, Godefay H, Prata N. Community health workers as social marketers of injectable contraceptives: a case study from Ethiopia. Glob Health Sci Pract. 2017;5(1):44-56. https://doi.org/10.9745/ GHSP-D-16-00344.

34. Okegbe T, Affo J, Djihoun F, Zannou A, Hounyo O, Ahounou G, et al. Introduction of community-based provision of subcutaneous depot medroxyprogesterone acetate (DMPA-SC) in Benin: programmatic results. Glob Heal Sci Pract Sci Pract. 2019;7(2):228-39.

35. Advancing Partners \& Communities. Provision of Injectable Contraceptives by Community Health Workers Evidence from Groundbreaking Pilots. 2014; 1-4. Available from: https://www.advancingpartners.org/sites/default/files/ apc_advocacy_pack_1.pdf.

36. World Health Organization; U. S Agency for International Development (USAID) ; Family Health International (FHI). Conclusions from a Technical Consultation: Community-Based Health Workers Can Safely and Effectively Administer Injectable Contraceptives. 2010;(June). Available from: https:// www.fhi360.org/sites/default/files/media/documents/community-basedinjectables-safe-effective.pdf.

37. USAID/ Africa Bureau. Three successful Sub-Saharan Africa family planning programs: lessons for meeting the MDGs. 2012;1-31. Available from: https:// www.fhi360.org/sites/default/files/media/documents/africa-bureau-casestudy-report.pdf.

38. Becker S. Couples and reproductive health: a review of couple studies. Stud Fam Plan. 1996;27(6):291-306.

39. Vouking MZ, Evina CD, Tadenfok CN. Male involvement in family planning decision making in sub-Saharan Africa- what the evidence suggests. Pan Afr Med J. 2014;19:1-5.

40. Easterlin RA, Crimmins EM. The fertility revolution : a supply-demand analysis Vol. 16. Contemporary Sociology A Journal Of Reviews; 1985. xix, 209 p.

41. Easterlin RA, Wongboonsin K, Ahmed MA. No title. Stud Fam Plan. 1988; 19(5):257-69. 
42. Population Center [CPC]. MEASURE EVALUATION. The importance of gender in family planning and reproductive health data. 2017;(March). Available from: https://www.measureevaluation.org/resources/publications/fs-17-205 b/at_download/document

43. Ross J, Hardee K. Access to contraceptive methods and prevalence of use. J Biosoc Sci. 2013;45(6):761-78.

44. Ross J, Stover J. Use of modern contraception increases when more methods become available: analysis of evidence from 1982-2009. Glob Heal Sci Pract. 2013;1(2):203-12.

45. Bongaarts J, Bruce J. The causes of unmet need for contraception and the social content of services. Stud Fam Plan. 1995;26(2):57-75.

46. Bruce J. Fundamental elements of the quality of care: a simple framework. Stud Fam Plan. 1990;21(2):61-91.

47. Sullivan TM, Bertrand JT, Rice J, Sheldon JD. Skewed contraceptive method mix: why it happens, why it matters. J Biosoc Sci. 2006:38:501-21.

48. High-impact Practices in Family Planning (HIPs). Social and Behavior Change: a critical part of effective family planning programs. 2018;1-4 Available from: https://healthcommcapacity.org/hc3resources/servicecommunication-implementation-

49. Family Planning High Impact Practices. Community Group Engagement: Changing Norms to Improve Sexual and Reproductive Health. 2016; Available from: http://www.fphighimpactpractices.org/

50. Pariani S, Heer DM, Van Arsdol MD. Does choice make a difference to contraceptive use? Evidence from East Java. Stud Fam Plan. 1991;22(6):384-90.

51. Phillips JF, Hossain MB, Huque A, Akbar J. A case study of contraceptive introduction: domiciliary depot-medroxy progesterone acetate services in rural Bangladesh. In: Segal SJ, Tsui A, Rogers SM, editors. Demographic and programmatic consequences of contraceptive innovations. New York: Plenum Press; 1989. p. 227-48.

52. Phillips JF, Stinson WS, Bhatia S, Rahman M, Chakraborty J. The demographic impact of the family planning--health services project in Matlab. Bangladesh Stud Fam Plann. 1982;13:131-40.

53. Stinson WS, Phillips JF, Rahman M, Chakraborty J. The demographic impact of the contraceptive distribution project in Matlab, Bangladesh. Stud Fam Plann. 1982:13:141-8.

\section{Publisher's Note}

Springer Nature remains neutral with regard to jurisdictional claims in published maps and institutional affiliations.

Ready to submit your research? Choose BMC and benefit from:

- fast, convenient online submission

- thorough peer review by experienced researchers in your field

- rapid publication on acceptance

- support for research data, including large and complex data types

- gold Open Access which fosters wider collaboration and increased citations

- maximum visibility for your research: over $100 \mathrm{M}$ website views per year

At $\mathrm{BMC}$, research is always in progress.

Learn more biomedcentral.com/submissions 